UCRL - 9104.1

PREPRINT

$$
\text { CENF- } 841117 \ldots 17
$$

\title{
ION SOURCE DEVELOPMENT AT RTNS-II
}

D. Massoletti

D. W. Heikkinen

This paper was prepared for submittal to The Eighth Conference on the Application of

Accelerators in Research and Industry November 12-14, 1984

Denton, Texas

\section{September 26,1984}

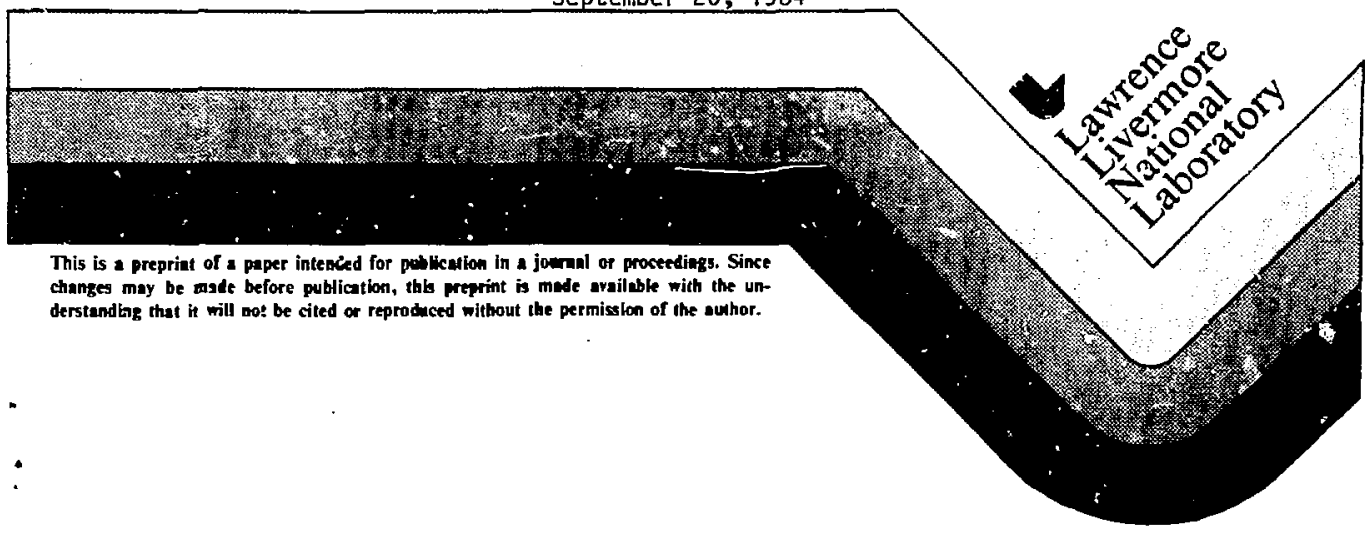

DISTHBUTIOH OF IHIS OOCYBSET IS IMLIMTEO 


\section{DISCI.AIMIER}

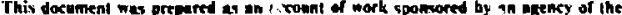
United Sintes Coverwiment. Neither the Unired Siaken Gesernment nor the Univenity

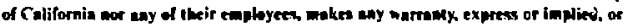

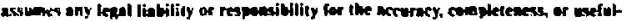
ness of any iaformation, apraratus, product, of precess dikclowel of represents that

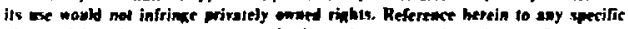

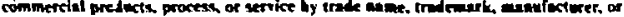
aherwise, does not necrsuarily constitute or imply its endersement recommendation. of is vorian by the Unired seates Goverament or the University of Californic. The views and epinions of anthors expressed hertia do not mecessarily slate or reflect thane of the United Salis Govesnment or the University of Californit, and shall not be uspd for advertising or prodect endorsement parposes. 
ION SOURCE DEVELOPMENT AT RTNS-II*

D. Massolett1 and D. W. Heikkinen

Lawrence Livermore Naticnal Laboratory, Livermore CA 94550

UCRL--91041

$2585 \quad 003133$

Abstract

Results are reforted for an ongoing effort to optimize $\mathrm{D}^{+}$beam production by the MATS-III ion source used at RINS-II. The characteristics of the source have been determined. Particular attention was paid to the extraction geometry and plasma production. The plasma spatial and temporal uniformity has been examined. The seven aperture triode geometry has been varied to optimize neutron production. This includes beamlet steering and electrode gapping as well as aperture shaping.

* Work performed under the auspices of the U.S. Department of Energy and Japan (Monbusho) by Lawrence Livermore National Laboratory under contract Number W-7405-ENG-48. 


\section{Introduction}

The design of the neutron sources at the Rotating Target Neutron Source-II (RTNS-II) [1] specified a deuteron beam spot size of approximately 1-cm diameter on target and a beam current of $150 \mathrm{~mA}$ to produce a neutron source strength of $4 \times 10^{13} \mathrm{n} / \mathrm{s}$. The ion source of choice for this facility several years ago, was the MATS-III [z], described elsewhere in detail. Since that time, the maximum source operating voltage has been raised from $25 \mathrm{kV}$ to $35 \mathrm{kV}$ and the arc power extended to $5 \mathrm{~kW}$. The current to target has been increased from the $45 \mathrm{~mA}$ achieved at initial operation to $130 \mathrm{~mA}$ in approximately the same spot size. Further advances in achieving higher than $135 \mathrm{~mA}$ on target necessitated the characterization of the MATS-III ion source performance and determination of inherent limitations. To this end examinations were made of the plasma source, the extraction geometry, and component ljfetimes.

\section{Plasma Source Characteristics}

Experiments were conducted to verify plasma source performance and monitor the effects of changes for improvement using first one probe and subsequently two probes set 180 degrees apart on a plane close to the plasma electrode to establish the plasma density and arc power relationship by measuring the saturated ion current, as shown in Fig. 1. In the two probe cases it was possible to observe the 180 degree phase-shift expected with a flute instability. Verification was thus made of a rotational Erequency of approximately $330 \mathrm{kHz}$, just as had been reported in the Iiterature (See ief. 1) when hydrogen gas had been used. However, neither the percentage of modulation nor frequency were found to have dependences as suggested for a flute instability. Indeed the variation in modulation 
was independent of power level and axial magnetic field strength, but seemed only somewhat dependent on arc voltage, ranging from \pm 308 to \pm 408 between $2 \mathrm{~kW}$ to $5 \mathrm{~kW}$ arc power.

The plasma current density, taken to be proportional to the saturated ion current, was measured with the probe biased at -20 volts with respect to cathode. At $5 \mathrm{~kW}$ of arc power the current density (j) was $250 \mathrm{~mA} / \mathrm{cm}^{2}$ with a temporal non-miformity of $\pm 40 \%$. Some improvement had been noticed from preliminary test results with a change in zwischen position that both increases plasma density and reduces somewhat the peak-to-peak modulation, but no significant imqrovernent (i.e. $>108$ ) was obtained. This change has not yet been implemented on production sources.

3. Single Aperture Operation

To confirm probe data, plugs were variously placed in six of the seven plasma elecinode apertures to determine the nature of the beamlets from different positions in the aperture array and therefore different regions of the plasma front. This also alters beamlet position in tems of the double-focusing bend magnet. The effect of the loss of beamlet interaction is considered small and is thus ignored. Another possible influence may be in the shift in neutralization efficiency which, although not measured, is also considered to be small and is ignored. Fran the peak-voltage, peak-current cata, we can surmise a plasma non-uniformity from central to peripheral apertures at the plasma elcstrode to be on the order of \pm 408 . The data obtained from single aperture operation is shom in Taule I.

The effects of tenporal non-uniformity may be seen in the data in Table I and from the plasma probe data (Fig.1). For seven apertures we obtain a 
Table.I. MATS-III Source Operation. Single Aperture Data taken at $4 \mathrm{~kW}$ arc power showing inferred plasma density, monitored currents, and percent $D^{+}$beam current.

\begin{tabular}{|c|c|c|c|c|c|c|}
\hline & $\begin{array}{c}V_{\text {ext }} \\
\mathrm{kV}\end{array}$ & $\begin{array}{c}I_{\text {ext }} \\
\mathrm{mA}\end{array}$ & $\begin{array}{c}I_{p t}(a) \\
m A\end{array}$ & $\begin{array}{l}j \\
m A\end{array}$ & $\begin{array}{l}j\left(D^{+}\right) \\
\mathrm{n}^{2} \\
\end{array}$ & $\begin{array}{c}I_{\text {pt }} / I_{\text {ext }}{ }^{(a)} \\
8 \\
\end{array}$ \\
\hline $\begin{array}{l}\text { ven Aperture } \\
\text { er aperture) }\end{array}$ & 27 & $\begin{array}{r}410 \\
59\end{array}$ & $\begin{array}{r}128 \\
19\end{array}$ & 128 & 40 & 31 \\
\hline ntral only & $\begin{array}{l}27 \\
31 \\
33\end{array}$ & $\begin{array}{l}70 \\
80 \\
90\end{array}$ & $\begin{array}{l}21 \\
26 \\
24\end{array}$ & $\begin{array}{l}153 \\
175 \\
197\end{array}$ & $\begin{array}{l}45 \\
57 \\
52\end{array}$ & $\begin{array}{l}29 \\
32 \\
26\end{array}$ \\
\hline
\end{tabular}

(a) $I_{\text {pt }}$ refers to bean measured after the bend magnet.

current of $126 \mathrm{~mA}_{\mathrm{cm}}{ }^{2}$, which is the modulation minima. The central aperture has a current equal to the mean plasma fluctuation, $180 \mathrm{~mA} / \mathrm{cm}^{2}$, and the peripheral apertures have the nms value of the modulation, $195 \mathrm{ma} / \mathrm{cm}^{2}$. The yield from the optimum current density is approximately 408 and 308 higher per aperture respectively than the aggregate, which reinforces that the spatial difference is only a radial density variation.

The tuned voltage for the central aperture was $4 \mathrm{kV}$ higher than the seven-aperture case, while for the peripheral apertures it was 6 kV higher. Although $\mathrm{v}^{3 / 2}$ scaling can only be rigorously apjlied in cases of uniform plasna for yields at tuned voltages, we can see that the central aperture datz does indeed scale with voltage as $v^{3 / 2}$. Assuming $v^{3 / 2}$ scaling for the peripheral apertures at $27 \mathrm{kV}$, we would expect $I_{p t}$ to be $18 \mathrm{~mA}$. If we then assume the seven-aperture source to yield the sum of the central and six peripheral aperture scaled values, the expected current would be $129 \mathrm{~mA}$, which is what we do indeed see. 
The only (impractical) solution would be to tailor the aperture diameter, spacing, and displacements to conform to these variations. This we did not do.

\section{Extractor Geometry}

The MATS-III ion source gap spacing, aperture displacement and electrode voltages used in initial operation yielded a focal length of about $63 \mathrm{~cm}$ according to calculations based upon Conrad [3]. In the process of going to higher extraction voltages the first gap distance and bending magnet field strength were increased proportionately. These changes resulted in a new focal length of approximately $68 \mathrm{~cm}$. At this point aperture arrays with different peripheral aperture offsets were tested to check for beanlet steering effects. Aperture offset was altered in $0.127 \mathrm{~mm}$ increments to give divergent, parallel, and three angles of convergent steering. The data is shown in Fig. 2. The basis for determination of the optimum focal length was made from beam transport measurements through the accelerator and beam transport system best seen as the ratio of target current to extraction current. Because the focal length of the source is mainly a function of the gap spacing and the offset distance and only slightly effected by the gap voltages, the extraction voltage and the bend magnet field strength were kept constant. The offset chosen was $0.254 \mathrm{~mm}$ for a focal length of $71 \mathrm{~cm}$.

To perform these tests it was easier to make the decel electrode apertures in a molybdenum plate without water cooling capability. Since this electrode suffers the highest heat load and sputtering, we were able to establish the desirability of future manuracture using this material rather than the copper parts currently used. 'tha MATS-III ion 
source employs displacement of both the decel and ground electrodes with respect to the plasma electrode for beamlet steering. According to Conrad (See ref. 2) the best choice for constant deflection through a broad operating range is for the decel electrode to be displaced in relation to the plasma and ground electrodes instead. This will be considered for use in the future.

\section{Shaped Apertures}

The MATS-III ion source in use has three copper electrodes, each with seven cylindrical apertures. The diameters, starting with tine plasma electrode, are: $7.6 \mathrm{~mm}, 5.3 \mathrm{~mm}$, and $6.3 \mathrm{~mm}$. Since work has been reported in the literature [4] utilizing the same diameter for all apertures, a special set of electrodes was made to obtain comparable data. Two alternatives to the cylindrical aperture were chosen. One with a bevel in the plasma electrode on the plasma side and the other with the bevel on the decel electrode side. In contrast to work reported above, we found the cylindrical apertures not to be our worst case. Indeed, the aperture with the bevel on the plasma side suggested as providing the best perfomance yielded poor results. Approximately 108 higher $\mathrm{D}^{+}$beam was seen with the aperture beveled on the decel electrode side. Although this feature has not as yet been implemented on the production sources, in the present configuration and with present power levels, this may be translated into about $145 \mathrm{~mA} \mathrm{D}^{+}$on target.

Figure 3 shows low level arc power tests giving arc power, $\mathrm{D}^{+}$beam current, and extraction current as a function of extraction voltage for the various aperture shapes.

6. Component Lifetimes

In addition to investigating the enhancement of electrode lifetime, a change was made in the filament and arc return circuitry for the 
oxide-coated tantalum filaments as shom in Fig. 4. In azdition the cathode assembly was modified so that molytodenum holders are used for the filament connections. Also higher current capacity connectors were instalied outside the vacuum. It is not yet clear that the lifetime of the cathodes has been extended over previous operation, but the increased aro and filamert power requirements have at least been accommodated.

? Conclusions

Now that these limitations of the MAIS-III ion source have been examined we must r.ow look for other plasma sources that are currently available and prepare for their examination on an ion source test facility which will simulate the ion source arrangement at RTNS-II.

We wish to thank the RINS-II Operations, Mechanical, ard Electronics Staffs for their support and tecinical contributions. 


\section{References}

1. D. W. Heikkinen and C. M. Lugan, Proc. Int'1 Ion Engrg, Congress ISIAT'83 \& IPAT'83, KYULO (1983) 555.

2. J. E. Osher and G. W. Hamilton. Proc. of the Second Symposium on Ion Sources $\mathrm{s}$ Formation of Ion Beams; Lawrence Berkeley Laboratory, LBL 3399 (1974)

3. J. R. Conrad, Rev. Sci. Instrum. 51(4) (1980) 418.

4. I. R. Grisham, et al., Rev. Sci. Instrum. 48 (1977) 1037.

\section{FIGURE CAPTIONS}

Fig. 1. Plasma current density from snturated ion current as a function of arc power for the MATS-III source. Exror bars indicate peak-to-peak modulation at $330 \mathrm{kHz}$.

Fig. 2. Beanlet steering effect as a function of offset distance, all other parameters constant.

- ratio of target current to plunging target current ( $I_{p t}$ ),

$x$ ratio of plunging target current to extraction current, ratio of target current to extraction currert.

Fig. 3. Plasma electrode aperture shape test data.

- bevel on decel electrode side. cylinarical aperture,

$x$ bevel an plasma side.

Fj.g. 4. (a) MATS-III original arc-filament circuit, and

(b) present arc-GiJament circuit confics:zation. 


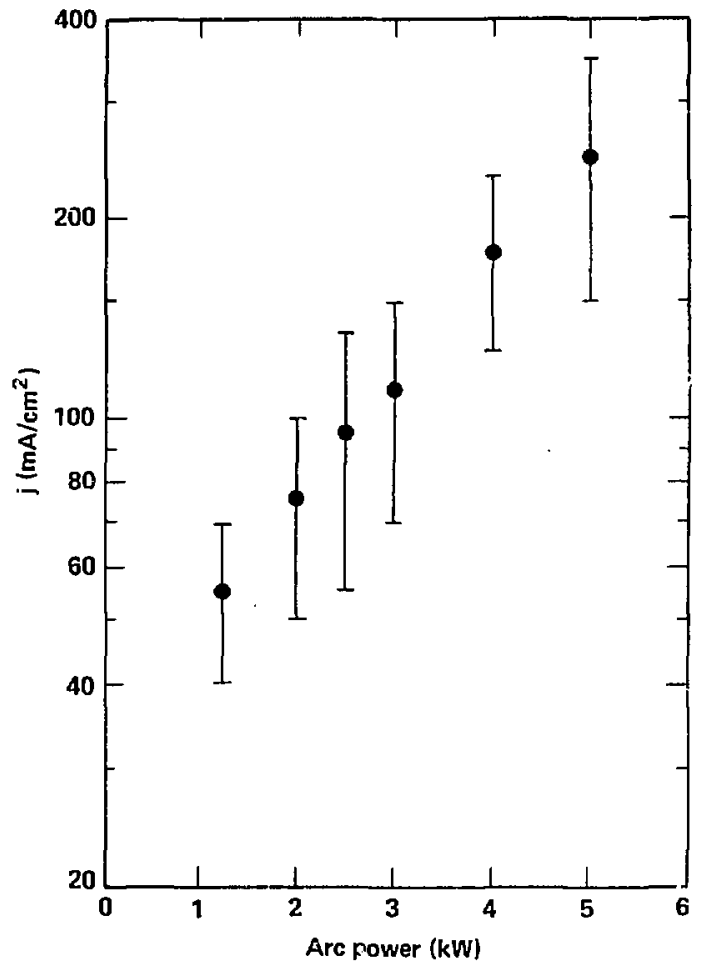

Fig. 1. Plasma current density from saturated ion current as a function of arc power for the MATS III source. Error bars indicate peak to peak modulation at $330 \mathrm{kHz}$. 


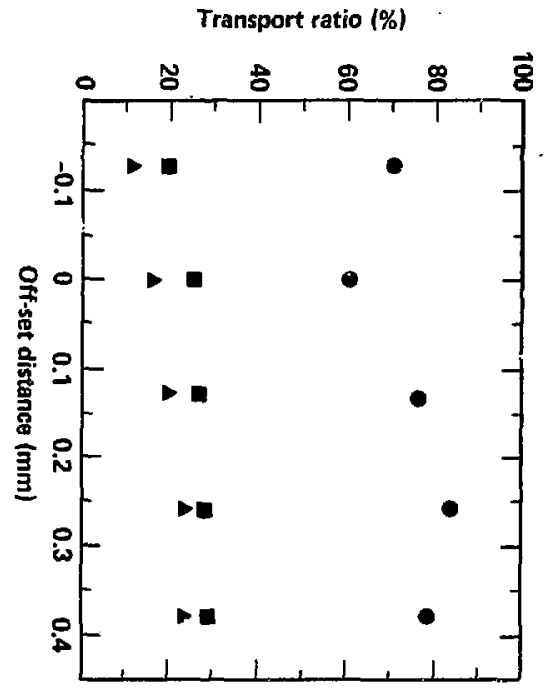

Fig. 2. Beamlet steering effect as a functi on of off-set distance, all other parameters constant. Where: - ratio of target current to plunging target current ( $I_{p t}$ ); a ratio of plunging target current to extraction currert; - ratio of target current to extraction current. 


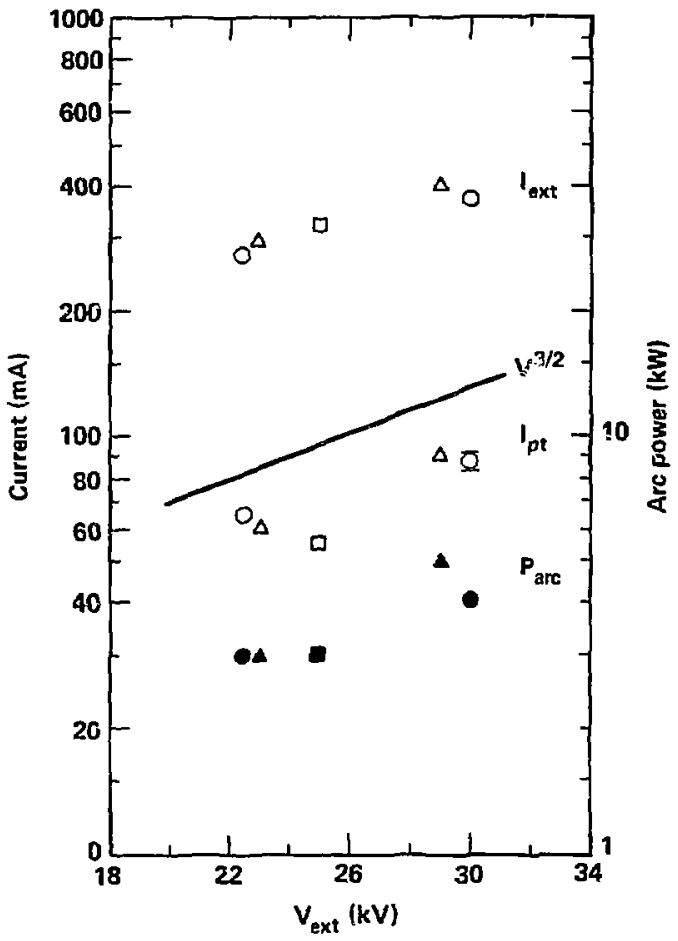

Fig. 3. Flasma electrode aperture shape test data. Where: - bevel on the decel electrode side; cylindrical aperture; bevel on the plasma side. 

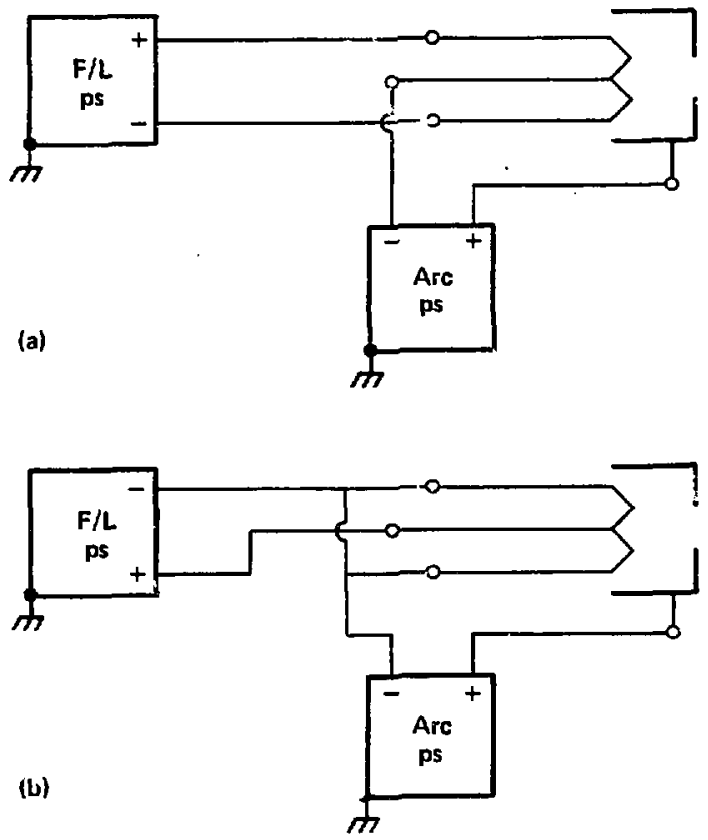

Fig. 4. MATS III original arc-filament circuit (a), and present arc-filament circuit configuration (b). 